\title{
What Else Is Broken? Can We Fix It?
}

\author{
Yale Patt \\ The University of Texas at Austin
}

\begin{abstract}
The founder and soul of this conference, Professor Stamatis Vassiliadis, always wanted a Keynote on the beach. A keynote without PowerPoint, air conditioning, and all the other usual comforts of keynotes, comforts both for the speaker and for the audience. After all, the great thinkers of this ancient land did their thinking, teaching, and arguing without PowerPoint and without air conditioning. But they were they and we are we, and no sane SAMOS keynote speaker would put himself in the same league with those masters.

Nonetheless, Stamatis wanted it, and I never found it easy to say no to Stamatis, so last year at SAMOS VIII, I agreed to give a Keynote on the Beach. It has been subsequently relabeled The Beachnote, and I have been asked to do it again.

The question of course is what subject to explore in this setting, where the sound of the speaker's voice competes with the sounds of the waves banging against the shore, where the image of the speaker's gestures competes with the image of the blue sky, bright sun, and hills of Samos. I decided last summer to choose a meta-topic, rather than a hard core technical subject: "Is it broken," with particular emphasis on professors - are they ready to teach, are they ready to do research, and students are they learning, is their education preparing them for what is needed after they graduate.

My sense is that for this environment, a meta-topic is the right model, and so I propose to visit it again. For example: our conferences and journals. Are they broken? Can we fix them? Somewhat more technical: The interface between the software that people write to solve problems and the hardware that has to run that software. Is it broken? Can we fix it? These are just examples of some of the things we might explore in this year's Beachnote. As I said last year, I will welcome other suggestions from the audience as to what they think is broken. My hope is to have us all engaged in identifying and discussing some of the fundamental problems that plague our community.
\end{abstract}

